\title{
Experience with Open and Laparoscopic Surgery for Primary Gastric Stromal Tumors in a Single Institute
}

\author{
Yi-Hsuan Hu',2,5, Kuo-Hung Huang1,6, Yuan-Tzu Lan 3,5, Jen-Hao Chen",7, Su-Shun Lo,8, \\ Anna Fen-Yau Li ${ }^{4,5}$, Shih-Hwa Chiou ${ }^{6,9,10}$, Chew-Wun Wu1,5, Yi-Ming Shyr ${ }^{1,5}$, Wen-Liang Fang1,5* \\ ${ }^{1}$ Division of General Surgery, Department of Surgery, Taipei Veterans General Hospital, Taiwan \\ ${ }^{2}$ Division of General Surgery, Department of Surgery, Cardinal Tien Hospital, Taiwan \\ ${ }^{3}$ Division of Colon \& Rectal Surgery, Department of Surgery, Taipei Veterans General Hospital, Taiwan \\ ${ }^{4}$ Department of Pathology, Taipei Veterans General Hospital, Taiwan \\ ${ }^{5}$ National Yang-Ming University, Taiwan \\ ${ }^{6}$ Institute of Clinical Medicine, School of Medicine, National Yang-Ming University, Taiwan \\ ${ }^{7}$ Cheng Hsin General Hospital, Taiwan \\ ${ }^{8}$ National Yang-Ming University Hospital, Taiwan \\ ${ }^{9}$ Department of Medical Research and Education, Taipei Veterans General Hospital, Taiwan \\ ${ }^{10}$ Institute of Pharmacology, National Yang-Ming University, Taiwan
}

Email: *s821094@hotmail.com

How to cite this paper: Hu, Y.-H., Huang, K.-H., Lan, Y.-T., Chen, J.-H., Lo, S.-S., Li, A.F.-Y., Chiou, S.-H., Wu, C.-W., Shyr, Y.-M. and Fang, W.-L. (2017) Experience with Open and Laparoscopic Surgery for Primary Gastric Stromal Tumors in a Single Institute. Surgical Science, 8, 229-239. https://doi.org/10.4236/ss.2017.86026

Received: May 3, 2017

Accepted: May 30, 2017

Published: June 2, 2017

Copyright $\odot 2017$ by authors and Scientific Research Publishing Inc. This work is licensed under the Creative Commons Attribution International License (CC BY 4.0).

http://creativecommons.org/licenses/by/4.0/

\begin{abstract}
Laparoscopic surgery has become increasingly popular in the management of gastric gastrointestinal stromal tumors (GISTs) in recent years. One hundred and forty-five patients underwent curative resections of primary gastric stromal tumors between September 2002 and March 2012 were assigned to either an open surgery group $(n=99)$ or a laparoscopic surgery group $(n=$ 46). In the open surgery group, there was a significantly higher number of samples with a mitotic index $\geq 10(16.1 \%$ vs. $0 \%)$, more tumors located in the gastric cardia (13.1\% vs. $6.5 \%)$, greater operative blood loss $(80 \mathrm{~mL}$ vs. $50 \mathrm{~mL})$ and a longer postoperative hospital stay (10 days vs. 6 days) than in the laparoscopic group. The surgical morbidity and mortality were $6.1 \%$ and $0 \%$ in the open group, whereas no complication or mortality in the laparoscopic group. Ten patients in the open group had tumor recurrences and no recurrence in the laparoscopic group. Multivariate analysis showed that tumor size and mitotic index were two independent risk factors associated with tumor recurrence. The 3-year disease-free survival rates and 5-year overall survival rates were similar between the two groups. The laparoscopic approach is a safe alternative procedure for gastric GISTs.
\end{abstract}




\section{Keywords}

GIST, Open, Laparoscopic, Tumor Size, Mitotic Index

\section{Introduction}

Gastrointestinal stromal tumors (GISTs) are the most common mesenchymalderived tumors in the gastrointestinal tract, resulting from the mutation of the receptor protein tyrosine kinase, KIT, also called CD117. [1] [2] Approximately $60 \%-70 \%$ of GISTs are located in the stomach. [3] Targeted therapy with KIT tyrosine kinase inhibitors has provided promising results in the management of metastatic GISTs in an adjuvant setting. However, surgery is still the mainstay of the curative treatment of primary GISTs.

A small resection margin, $0.5-1 \mathrm{~cm}$, is sufficient for the resection of GISTs. As a result, the wedge resection is the recommended procedure. However, a large tumor size or a tumor located at the esophagogastric junction or in the pre-pyloric region will create difficulties with a wedge resection. In such instances, a more extensive resection such as a combined organ resection, subtotal gastrectomy, or even a total gastrectomy, may be possible.

Laparoscopic resection for gastric GISTs has been reported to be a safe alternative procedure. [4]-[11] In comparison with open surgery, the laparoscopic approach was associated with less operative blood loss and a shorter postoperative hospital stay. The surgical morbidity, mortality and oncologic outcomes were similar between procedures. [9] However, most surgeons prefer open surgery in cases with a large tumor size or a tumor located at the esophagogastric junction, because of the technical difficulty in laparoscopic approach due to the increased difficulty of the suturing technique. With the aid of robotic-assisted surgery, the limitations of size and location in laparoscopic surgery for gastric GISTs may be modified and overcome in the future.

The aim of this study was to compare the surgical outcomes between open and laparoscopic surgery for primary gastric GISTs in a single institute in Taiwan.

\section{Materials and Methods}

Based on a prospective gastric cancer database in the Department of Surgery of Taipei Veterans General Hospital, between September 2002 and March 2012, 152 patients received surgery for primary gastric GISTs. Among them, seven patients had distant metastases. A total of 145 patients who underwent a curative resection of a gastric GIST were enrolled in this study. The exclusion criteria included the presence of a synchronous gastric cancer, a previous history of surgery for gastric cancer, or an incidental finding of a gastric GIST during surgery for other malignancies.

All GISTs were confirmed by the same pathologist. The mitotic index was defined as the number of mitoses per 50 high-power fields (HPF). The resected 
GISTs were divided into four groups (very low risk, low risk, intermediate risk, high risk) according to the National Comprehensive Cancer Network (NCCN) guidelines in 2007 [12].

A combined organ resection was performed to achieve a curative resection. The patients were evaluated by gender, age, tumor size, tumor location, operative approaches, combined organ resection, and the mitotic index. Operative outcomes such as operative blood loss, operative time, postoperative hospital stay, surgical morbidity and related morality were compared between the two groups.

\section{Surgical approaches}

Open surgery was performed with an upper midline abdominal incision. For the laparoscopic approach, a pneumoperitoneum was established through the periumbilical port. An infraxyphoid port was created for the insertion of a Nathanson liver retractor [13] (Cook Surgical, Bloomington, IN, USA) for lifting the left lobe of the liver to expose the upper stomach and the lower esophagus. Additional three ports were created for the resection of the gastric tumor. Indian ink marking was performed preoperatively for small gastric tumors to better locate the tumors during surgery. A wedge resection of the gastric tumor was performed using an endoGIA stapler or suturing technique. The tumor was placed in a tissue bag and removed from the periumbilical wound. For tumors that were located at the esophagogastric junction and difficult to suture intracorporeally, robotic-assisted laparoscopic surgery was performed. The setup of the robotic arms was the same as our previous report [14].

\section{Perioperative Management}

Routine nasogastric intubation was performed in the open surgery, while no nasogastric tube intubation was applied in the laparoscopic group. Most of the patients received continuous intravenous administration or an epidural injection of mixed analgesics for 3 - 4 days after surgery. Water was started on postoperative day 2, and a soft diet was started on postoperative day 3 to day 5 . The patient was discharged if no complications occurred.

\section{Follow-up}

Overall survival was calculated from the time of surgery until a recurrence or the last follow-up contact. None of the patients received adjuvant therapy preoperatively. Since February 2011, the National Health Insurance in Taiwan has allowed patients with a tumor size $\geq 6 \mathrm{~cm}$ to receive adjuvant imatinib (400 $\mathrm{mg}$ per day orally) for 12 months after curative surgery. Patients may receive sunitinib after the failure of imatinib due to either resistance or intolerance. Mutational analyses of KIT exons 9, 11, 13, and 17 and PDGFRA exons 10, 12, 14 and 18 may be performed for patients with tumor recurrences.

Follow-up assessments were performed every 3 months for the first 5 years after surgery, and then every 6 months until the patient's death. The follow-up procedures included a chest radiograph, an abdominal sonogram or CT scan, and an upper gastrointestinal endoscopy.

Biopsy sampling was performed to confirm the evidence of recurrent disease 
or distant metastases. Patients with tumor recurrences received target therapy with imatinib as the first line and sunitinib as the second line.

\section{Statistical Analysis}

Statistical analysis was performed using SPSS 13.0 (Statistic Package for Social Sciences; SPSS Inc., Chicago, IL, USA). The categorical data were compared by a $\chi^{2}$ test with Yates correction or Fisher's exact test. The continuous variables were compared among the two groups with the independent Student's t-test. Cox proportional hazards models were used to explore the association of clinical parameters with tumor recurrence. A $P$ value $<0.05$ was considered to be statistically significant.

\section{Results}

A total of 145 patients receiving curative surgery for gastric GISTs were enrolled in this study. The flow chart and surgical outcomes of this study are shown in Figure 1. Open surgery was performed in ninety-nine patients, and the laparoscopic approach was performed in 46 patients. The patients were divided into open surgery and laparoscopic groups.

As shown in Table 1, there was no significant difference between the two groups on age, gender, tumor size and tumor growth pattern. Open surgery was associated with a higher number of mitotic indexes $\geq 10$ per $50 \mathrm{HPF}$, a higher number of intermediate and high-risk GISTs, and a higher number of tumors located in the gastric cardia, compared with the laparoscopic approach. There

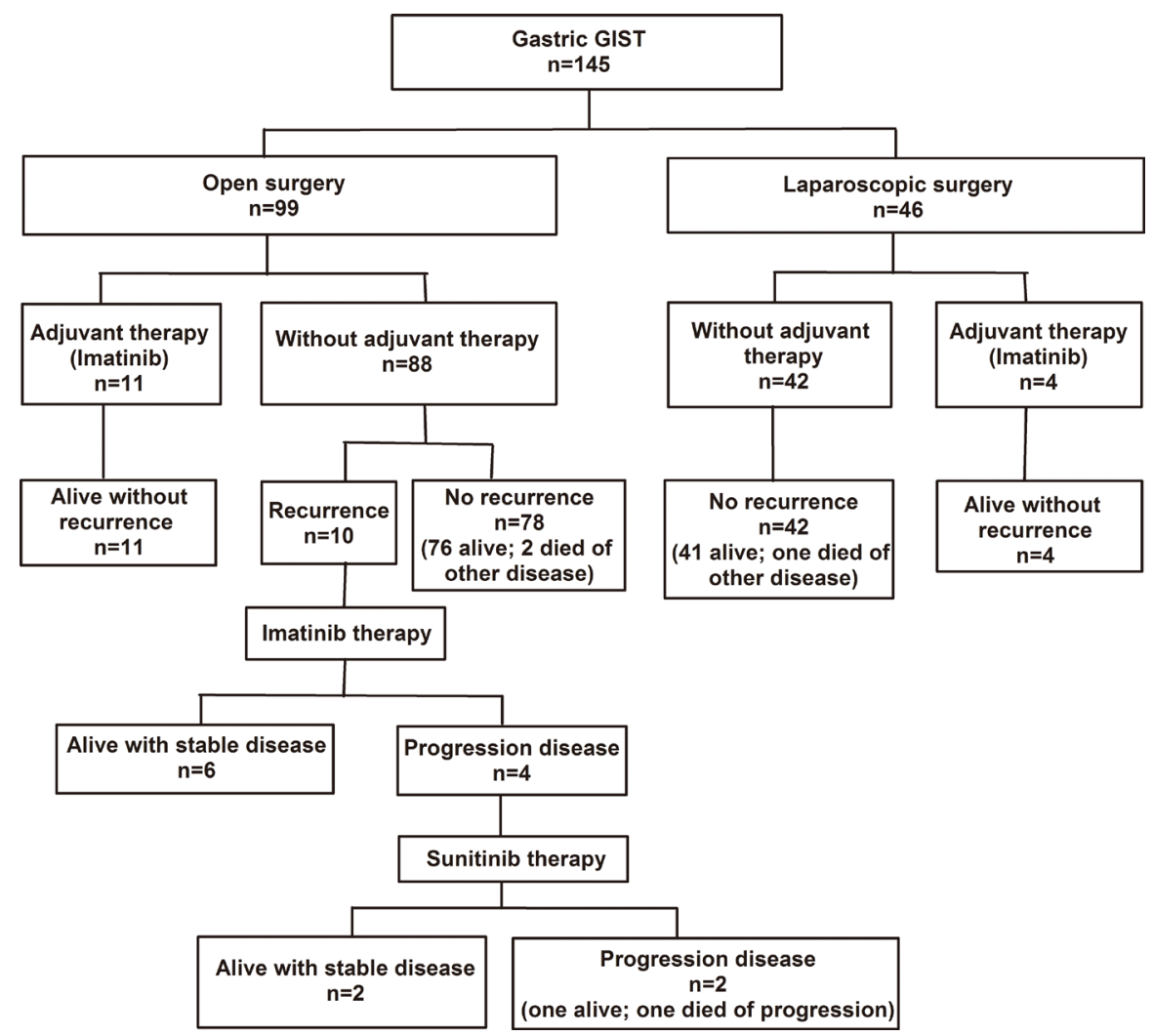

Figure 1. The flowchart of this study. 
Table 1. Clinicopathological differences between open and laparoscopic surgery for primary gastric stromal tumors.

\begin{tabular}{|c|c|c|c|}
\hline & $\begin{array}{l}\text { Open surgery } \\
\qquad \begin{array}{c}(\mathrm{n}=99) \\
\mathrm{n}(\%)\end{array}\end{array}$ & $\begin{array}{l}\text { Laparoscopic surgery } \\
\qquad \begin{array}{c}(\mathrm{n}=46) \\
\mathrm{n}(\%)\end{array}\end{array}$ & $P$ value \\
\hline \multicolumn{4}{|l|}{ Age (years) } \\
\hline$<65$ & $41(70.7)$ & $22(47.8)$ & \\
\hline$\geq 65$ & $58(29.3)$ & $24(52.2)$ & 0.478 \\
\hline \multicolumn{4}{|l|}{ Gender } \\
\hline Male & $51(51.5)$ & $28(60.9)$ & \\
\hline Female & $48(48.5)$ & $18(39.1)$ & 0.371 \\
\hline \multicolumn{4}{|l|}{ Tumor maximal size $(\mathrm{cm})$} \\
\hline$<2 \mathrm{~cm}$ & $4(4)$ & $3(6.5)$ & \\
\hline $2-5 \mathrm{~cm}$ & $53(53.5)$ & $29(63)$ & \\
\hline$>5 \mathrm{~cm}$ & $42(42.5)$ & $14(30.5)$ & 0.355 \\
\hline \multicolumn{4}{|l|}{ Mitotic index (per $50 \mathrm{HPF}$ ) } \\
\hline$<5$ & $57(57.6)$ & $32(69.6)$ & \\
\hline $5-10$ & $26(26.3)$ & $14(30.4)$ & \\
\hline$>10$ & $16(16.1)$ & 0 & 0.015 \\
\hline \multicolumn{4}{|l|}{ Risk category† } \\
\hline Very low risk & $39(39.4)$ & $26(56.5)$ & \\
\hline Low risk & $16(16.2)$ & $11(23.9)$ & \\
\hline Intermediate risk & $17(63)$ & $7(15.2)$ & \\
\hline High risk & $27(27.4)$ & $2(4.4)$ & 0.010 \\
\hline \multicolumn{4}{|l|}{ Location of tumor } \\
\hline Cardia & $13(13.1)$ & $3(6.5)$ & \\
\hline Fundus, high body & $56(56.6)$ & $25(54.3)$ & \\
\hline Middle third stomach & $28(28.3)$ & $12(26.1)$ & \\
\hline Lower third stomach & $2(2)$ & $6(13.1)$ & 0.041 \\
\hline \multicolumn{4}{|l|}{ Tumor growth pattern } \\
\hline Intraluminal growth & $44(44.4)$ & $22(47.8)$ & \\
\hline Extragastric growth & $55(55.6)$ & $24(52.2)$ & 0.723 \\
\hline
\end{tabular}

$\dagger$ According to the NCCN guidelines in 2007.

was no conversion of the laparoscopic approach to open surgery. Robotic-assisted laparoscopic surgery was performed in only one 84-year-old patient with a $7-\mathrm{cm}$ tumor located above the posterior wall of the stomach near the esophagogastric junction. Preoperatively, the patient had renal insufficiency and coronary artery disease. The suturing technique for the closure of the gastric opening was assisted by robotic arms.

Operative outcomes

Table 2 shows that wedge resections are the most common operation in both 
Table 2. Operative outcomes after surgery for primary gastric stromal tumors.

\begin{tabular}{|c|c|c|c|}
\hline & $\begin{array}{c}\text { Open surgery } \\
(\mathrm{n}=99) \\
\mathrm{n}(\%)\end{array}$ & $\begin{array}{l}\text { Laparoscopic surgery } \\
\qquad \begin{array}{c}(\mathrm{n}=46) \\
\mathrm{n}(\%)\end{array}\end{array}$ & $P$ value \\
\hline \multicolumn{4}{|l|}{ Type of gastrectomy } \\
\hline Wedge resection & $78(78.8)$ & $42(91.3)$ & \\
\hline $\begin{array}{l}\text { Proximal subtotal gastrectomy and } \\
\text { jejunal pouch interposition }\end{array}$ & $5(5.1)$ & 0 & \\
\hline Distal gastrectomy & $8(8.1)$ & $4(8.7)$ & \\
\hline Total gastrectomy & $8(8.1)$ & 0 & 0.084 \\
\hline Combined organ resection $\dagger$ & $13(13.1)$ & $8(17.4)$ & 0.613 \\
\hline \multicolumn{4}{|l|}{ For curative intent } \\
\hline Liver & $5(5.1)$ & 0 & \\
\hline Spleen & $3(3)$ & 0 & \\
\hline Pancreas & $2(2)$ & 0 & \\
\hline Colon & $1(1)$ & 0 & \\
\hline \multicolumn{4}{|l|}{ Prophylactic surgery } \\
\hline Gallbladder & $4(4)$ & $8(17.4)$ & \\
\hline Operative time (min) & $170(55-415)$ & $160(80-420)$ & 0.884 \\
\hline Blood loss (mL) & $80(20-1650)$ & $50(10-900)$ & 0.016 \\
\hline Postoperative hospital stay (day) & $10(5-43)$ & $6(3-15)$ & $<0.001$ \\
\hline Surgical morbidity & $6(6.1)$ & 0 & 0.177 \\
\hline Anastomotic leakage & $1(1)$ & 0 & \\
\hline Delayed gastric emptying & $1(1)$ & 0 & \\
\hline Upper GI bleeding & $1(1)$ & 0 & \\
\hline Pancreatic stump leakage & $1(1)$ & 0 & \\
\hline Wound infection & $2(2)$ & 0 & \\
\hline Surgical mortality & 0 & 0 & 1.000 \\
\hline
\end{tabular}

GI: gastrointestinal; $\uparrow$ Some patients had more than one organ resection.

open (78.8\%) and laparoscopic (91.3\%) surgery for gastric GISTs. With regard to combined organ resections in open surgery, the most common organ was the liver $(5.1 \%)$, followed by the gallbladder (4\%), spleen (3\%), pancreas $(2 \%)$ and colon (1\%). In laparoscopic surgery, the gallbladder (17.4\%) was the only organ that was resected as well. Cholecystectomies in both open and laparoscopic surgery were performed because of cholelithiasis.

The median operative time was similar between the open and laparoscopic groups (170 vs. $160 \mathrm{~min}, P=0.884$ ). Open surgery was associated with a greater blood loss ( $80 \mathrm{~mL}$ vs. $50 \mathrm{~mL}, P=0.016)$ and a longer postoperative hospital stay (10 days vs. 6 days, $P<0.001)$ compared with the laparoscopic group.

There were six surgical morbidities in the open group, including two wound infections, followed by one anastomosis (duodenal stump) leakage, one delayed 
gastric emptying, one upper gastrointestinal bleeding and one pancreatic stump leakage. There was no surgical morbidity in the laparoscopic group. No surgical mortality was observed in both groups.

Adjuvant therapy and follow-up

As shown in Figure 1, there were more patients receiving adjuvant therapy with imatinib in the open group $(11 / 99,11.1 \%)$ than in the laparoscopic group $(4 / 46,8.7 \%)$. No tumor recurrence was observed in both groups with adjuvant therapy. However, among the 88 patients in the open group without adjuvant therapy, 10 patients had tumor recurrence; including 4 patients with liver metastases, 3 patients with peritoneum metastases, one patient with retroperitoneum metastasis, one patient with both liver and peritoneum metastases, and one patient with both liver and retroperitoneum metastases. All the 10 patients with tumor recurrence received imatinib therapy; among them, 6 patients had stable disease during follow-up, and 4 patients had drug resistance, and sunitinib was prescribed. Among the 4 patients with sunitinib therapy, 2 patients had stable disease, and 2 patients had disease progression. One patient died of tumor recurrence during follow-up. Mutational analyses of KIT exons 9, 11, 13, and 17 and PDGFRA exons 10,12, 14 and 18 were performed for the only patient who died from a tumor recurrence; the results showed a deletion mutation in exon 11 of KIT and a missense mutation in exon 13 of KIT.

The median follow-up time was longer in the open group than in the laparoscopic group (35.3 months vs. 18.5 months). During follow-up, three patients in the open group and one patient in the laparoscopic group died. The causes of the three deaths in the open group included one diffuse large B-cell lymphoma, one multiple myeloma, one GIST recurrence. There have been no tumor recurrences up to the present in the laparoscopic group. Only one patient died of urosepsis in the laparoscopic group.

Fifteen patients receiving adjuvant therapy were excluded from the analysis of risk factors for tumor recurrence, including 11 patients in the open group and 4 patients in the laparoscopic group. Univariate analysis showed that tumor size, mitotic index, and tumor growth pattern were associated with tumor recurrence. Multivariate analysis with a logistic regression stepwise procedure showed that both the tumor size and the mitotic index were significant indicators of a recurrence (Table 3). The 3-year disease-free survival rates were similar between open and laparoscopic groups $(84.5 \%$ vs. $90 \%, P=0.158$, Figure $2(\mathrm{~A}))$. The 5 -year overall survival rates were not statistically different between open and laparoscopic groups ( $94.9 \%$ vs. $90 \%, P=0.871$, Figure $2(\mathrm{~B})$ ).

\section{Discussion}

In the current study, the laparoscopic approach was associated with fewer high-risk GISTs, a lower mitotic index of the tumor, less operative blood loss and a shorter postoperative hospital stay than in the open group. Because this study was a retrospective analysis, there was some selection bias between the two groups. 
(A)

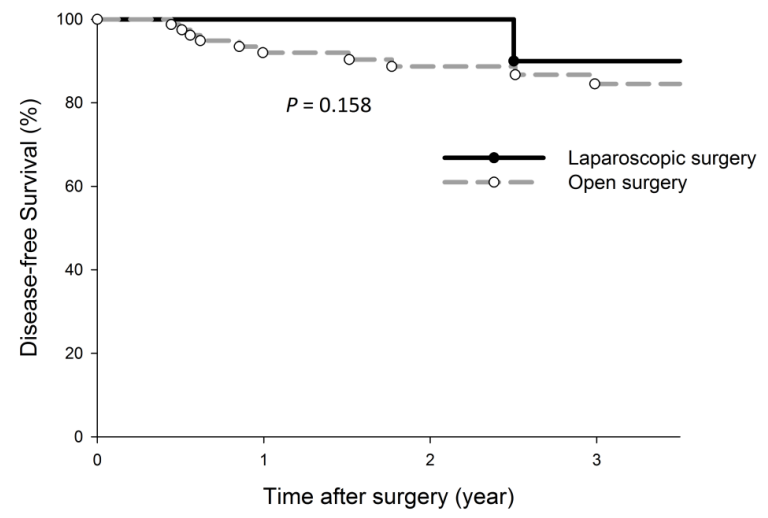

Patients at risk

Laparoscopic 42

Open 88
(B)



Patients at risk

$\begin{array}{lllllll}\text { Laparoscopic } & 42 & 42 & 42 & 41 & 41 & 41 \\ & 88 & 86 & 86 & 86 & 85 & 85\end{array}$

Figure 2. (A) The 3-year disease-free survival rates were similar between open and laparoscopic groups $(84.5 \%$ vs. $90 \%, P=$ 0.158). (B) The 5 -year overall survival rates were similar between open and laparoscopic groups ( $94.9 \%$ vs. $90 \%, P=0.871)$.

Table 3. Analysis of factors associated with recurrence after surgery for primary gastric stromal tumors without adjuvant therapy.

\begin{tabular}{|c|c|c|c|c|}
\hline & \multicolumn{2}{|c|}{ Univariate analysis } & \multicolumn{2}{|c|}{ Multivariate analysis } \\
\hline & Hazard ratio & $P$ value & Hazard ratio & $P$ value \\
\hline $\begin{array}{l}\text { Types of surgery } \\
\text { (Laparoscopic, open surgery) }\end{array}$ & 30.3 & 0.357 & & \\
\hline $\begin{array}{l}\text { Age (years) } \\
\qquad(<65, \geq 65)\end{array}$ & 0.96 & 0.953 & & \\
\hline $\begin{array}{l}\text { Gender } \\
\qquad \text { (Male, female) }\end{array}$ & 0.30 & 0.132 & & \\
\hline $\begin{array}{l}\text { Tumor maximal size }(\mathrm{cm}) \\
\qquad(<2,2-5,>5)\end{array}$ & 8.25 & 0.007 & 5.49 & 0.033 \\
\hline $\begin{array}{l}\text { Mitotic index (per } 50 \mathrm{HPF}) \\
\qquad(<5,5-10,>10)\end{array}$ & 5.48 & $<0.001$ & 4.31 & 0.001 \\
\hline $\begin{array}{l}\text { Tumor growth pattern } \\
\text { (intraluminal, extragastric) }\end{array}$ & 8.73 & 0.040 & & \\
\hline
\end{tabular}

DeMatteo et al. [15] demonstrated that tumor size and positive microscopic surgical margins determine survival after surgery for GISTs. It is therefore accepted that the surgical goal for GISTs should be a complete resection with gross negative margins without a lymphadenectomy. A wedge resection is the most frequently performed procedure, and it is the treatment of choice for gastric GISTs. [8] In our study, wedge resection was the most frequently performed procedure in both the open and laparoscopic groups $(78.8 \%$ and $91.3 \%$ respectively).

Our data showed that tumor size and mitotic index were independent risk 
factors for GIST recurrence after surgery. The surgical approach itself is not a risk factor affecting tumor recurrence. It is reasonable that tumor behavior is the main factor that determines recurrence or not. With low surgical morbidity, short hospitalization and accep table 3-year disease free survival rate, Novitsky et al reported that laparoscopic surgery is the preferred surgical approach for patients with small- and medium-sized gastric GISTs. Consequently, we suggest laparoscopic surgery as the first choice of surgical approach for selected patients with gastric GISTs.

A larger tumor size is associated with a greater possibility of adhesion and organ invasion, which will increase the difficulty of dissection and tumor removal. Other authors advocate the use of hand-assisted laparoscopic surgery in GISTs size larger than $5 \sim 8.5 \mathrm{~cm}$. [8] [15] Sokolich et al. [4] reported that minimally invasive surgery should not be precluded in a large tumor size of GISTs, even 20 $\mathrm{cm}$ in size. There are increasing literature reports on the safety and feasibility of laparoscopic surgery for the treatment of stomach GISTs. The NCCN guidelines were modified in 2007 to reflect this situation. Under the new guidelines, tumors up to $5 \mathrm{~cm}$ can be safely approached laparoscopically. In our study, $30.5 \%$ of patients in the laparoscopic group (Table 1) had a tumor size larger than $5 \mathrm{~cm}$ (largest up to $11 \mathrm{~cm}$ ). Although long-term follow-up is still needed for oncologic surveillance, we believe that in experienced hands, the $5-\mathrm{cm}$ criteria may be further expanded in the near future. Additionally, we report our initial experience with robotic-assisted wedge resection with a comparable clinical outcome to open surgery. Tumors near the EG junction and cardia are challenging to treat laparoscopically due to the risk of the gastric inlet narrowing and the increased demands of the suturing technique. [9] However, the laparoscopic approach is still feasible in selected patients. [16] The introduction of robotic surgery may help to overcome these technical problems. We believe that the limitations of tumor size and location of GISTs for laparoscopic or robotic-assisted approaches will be extended in experienced hands. Careful patient selection and preoperative imaging, as well as a precise evaluation are important for surgeons to determine which surgical approach is feasible and appropriate.

There are some limitations in this study. First, this is a retrospective and observation study; selection bias would exist. Second, surgeon's selection for the surgical approach would strongly bias the results. Third, patients with a large tumor size and possible requiring combined organ resection were often recommended open surgery, which would also cause the differences in the surgical outcomes between the open and laparoscopic groups.

\section{Conclusion}

The laparoscopic approach is a safe and feasible procedure for gastric GISTs. Robotic-assisted surgery might be helpful for tumors located in the gastric cardia where a delicate suturing technique is required in the closure of the gastric opening after tumor removal. However, open surgery should be considered in cases with obvious nearby organ invasion diagnosed by CT imaging preopera- 
tively. Surgeons should also be comfortable with their ability to recommend that their patients choose the most appropriate surgical approach. To lower the conversion rate, careful and rigorous patient selection for laparoscopic surgery is important.

\section{Acknowledgements}

This research was supported by Taipei Veterans General Hospital (V105C-129).

\section{Conflict of Interest}

All authors have no conflict of interest.

\section{Author Contributions}

Conceived and designed the experiments: YHH KHH YTL JHC SSL AFYL SHC CWW YMS WLF. Performed the experiments: KHH WLF JHC. Analyzed the data: WLF. Contributed reagents/materials/analysis tools: KHH WLF JHC. Contributed to the writing of the manuscript: YHH KHH YTL WLF.

\section{References}

[1] Sanborn, R.E. and Blanke, C.D. (2005) Gastrointestinal Stromal Tumors and the Evolution of Targeted Therapy. Clinical Advances in Hematology \& Oncology, 3, 647-657.

[2] D’Amato, G., Steinert, D.M., McAuliffe, J.C. and Trend, J.C. (2005) Update on the Biology and Therapy of Gastrointestinal Stromal Tumors. Cancer Control, 12, 4456.

[3] Miettinen, M. and Lasota, J. (2001) Gastrointestinal Stromal Tumors-Definition, Clinical, Histological, Immunohistochemical, and Molecular Genetic Features and Differential Diagnosis. Virchows Archiv, 438, 1-12. https://doi.org/10.1007/s004280000338

[4] Sokolich, J., Galanopoulos, C., Dunn, E., Linder, J.D. and Jeyarajah, D.R. (2009) Expanding the Indications for Laparoscopic Gastric Resection for Gastrointestinal Stromal Tumors. Journal of the Society of Laparoendoscopic Surgeons, 13, 165-169.

[5] Privette, A., McCahill, L., Borrazzo, E., Single, R.M. and Zubarik, R. (2008) Laparoscopic Approaches to Resection of Suspected Gastric Gastrointestinal Stromal Tumors Based on Tumor Location. Surgical Endoscopy, 22, 487-494. https://doi.org/10.1007/s00464-007-9493-4

[6] Nishimura, J., Nakajima, K., Omori, T., Takahashi, T., Nishitani, A., Ito, T. and Nishida, T. (2007) Surgical Strategy for Gastric Gastrointestinal Stromal Tumors: Laparoscopic vs. Open Resection. Surgical Endoscopy, 21, 875-878.

https://doi.org/10.1007/s00464-006-9065-Z

[7] Sexton, J.A., Pierce, R.A., Halpin, V.J., Eagon, J.C., Hawkins, W.G., Linehan, D.C., Brunt, L.M., Frisella, M.M. and Matthews, B.D. (2008) Laparoscopic Gastric Resection for Gastrointestinal Stromal Tumors. Surgical Endoscopy, 22, 2583-2587. https://doi.org/10.1007/s00464-008-9807-1

[8] Catena, F., Di Battista., M., Fusaroli, P., Ansaloni, L., Di, Scioscio, V., Santini, D., Pantaleo, M., Biasco, G., Caletti, G., and Pinna, A. (2008) Laparoscopic Treatment of Gastric Gist: Report of 21 Cases and Literature's Review. Journal of Gastrointestinal Surgery, 12, 561-568. https://doi.org/10.1007/s11605-007-0416-4 
[9] Karakousis, G.C., Singer, S., Zheng, J., Gonen, M., Coit, D., DeMatteo, R.P., and Strong, V.E. (2011) Laparoscopic versus Open Gastric Resections for Primary Gastrointestinal Stromal Tumors (GISTs): A Size-Matched Comparison. Annals of Surgical Oncology, 18, 1599-1605. https://doi.org/10.1245/s10434-010-1517-y

[10] Novitsky, Y.W., Kercher, K.W., Sing, R.F., and Heniford, B.T. (2006) Long-Term Outcomes of Laparoscopic Resection of Gastric Gastrointestinal Stromal Tumors. Annals of Surgery, 243, 738-745; Discussion 745-737. https://doi.org/10.1097/01.sla.0000219739.11758.27

[11] De Vogelaere, K., Van Loo, I., Peters, O., Hoorens, A., Haentjens, P. and Delvaus, G. (2012) Laparoscopic Resection of Gastric Gastrointestinal Stromal Tumors (Gist) Is Safe and Effective, Irrespective of Tumor Size. Surgical Endoscopy, 26, 23392345. https://doi.org/10.1007/s00464-012-2186-7

[12] Demetri, G.D., Benjamin, R.S., Blanke, C.D., Blay, J.Y., Casali, P., Choi, H., Corless, C.L., Debiec-Rychter, M., DeMatteo, R.P., Ettinger, D.S., Fisher, G.A., Fletcher, C.D., Gronchi, A., Hohenberger, P., Hughes, M., Joensuu, H., Judson, I., Le Cesne, A., Maki, R.G., Morse, M., Pappo, A.S., Pisters, P.W., Raut, C.P., Reichardt, P., Tyler, D.S., Van den Abbeele, A.D., von Mehren, M., Wayne, J.D., Zalcoberg, J. and NCCN Task Force. (2007) NCCN Task Force Report: Management of Patients with Gastrointestinal Stromal Tumor (GIST)-Update of the NCCN clinical practice guidelines. Journal of the National Comprehensive Cancer Network, 5, S1-29; quiz S30, 2007.

[13] Marudanayagam, R., Sandhu, B. and Hallissey, M. (2009) Novel Technique of Insertion of Laparoscopic Nathanson Liver Retractor. Annals of the Royal College of Surgeons of England, 91, 712-713. https://doi.org/10.1308/rcsann.2009.91.8.712

[14] Huang, K.H., Lan, Y.T., Fang, W.L., Chen, J.H., Lo, S.S., Hsieh, M.C., Li, A.F., Chiou, S.H. and Wu, C.W. (2012) Initial Experience of Robotic Gastrectomy and Comparison with Open and Laparoscopic Gastrectomy for Gastric Cancer. Journal of Gastrointestinal Surgery, 16, 1303-1310. https://doi.org/10.1007/s11605-012-1874-X

[15] DeMatteo, R.P., Lewis, J.J., Leung, D., Mudan, S.S., Woodruff, J.M. and Brennan, M.F. (2000) Two Hundred Gastrointestinal Stromal Tumors: Recurrence Patterns and Prognostic Factors for Survival. Annals of Surgery, 231, 51-58. https://doi.org/10.1097/00000658-200001000-00008

[16] Hwang, S.H., Park do, J., Kim, Y.H., Lee, K.H., Lee, H.S., Kim, H.H., Lee, H.J., Yang, H.K. and Lee, K.U. (2009) Laparoscopic Surgery for Submucosal Tumors Located at the Esophagogastric Junction and the Prepylorus. Surgical Endoscopy, 23, 1980-1987. https://doi.org/10.1007/s00464-008-9955-3 
Submit or recommend next manuscript to SCIRP and we will provide best service for you:

Accepting pre-submission inquiries through Email, Facebook, LinkedIn, Twitter, etc. A wide selection of journals (inclusive of 9 subjects, more than 200 journals)

Providing 24-hour high-quality service

User-friendly online submission system

Fair and swift peer-review system

Efficient typesetting and proofreading procedure

Display of the result of downloads and visits, as well as the number of cited articles Maximum dissemination of your research work

Submit your manuscript at: http://papersubmission.scirp.org/

Or contact ss@scirp.org 